\title{
Red/Green Currant and Sea Buckthorn Berry Press Residues as Potential Sources of Antioxidants for Food Use
}

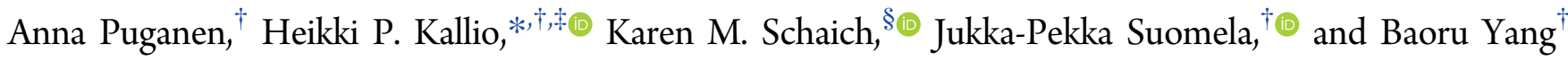 \\ ${ }^{\dagger}$ Food Chemistry and Food Development, Department of Biochemistry, University of Turku, FI-20014 Turku, Finland \\ ${ }^{\ddagger}$ The Kevo Subarctic Research Institute, University of Turku, FI-20014 Turku, Finland \\ ${ }^{\S}$ Department of Food Science, Rutgers University, 65 Dudley Road, New Brunswick, New Jersey 08901-8520, United States
}

\section{Supporting Information}

ABSTRACT: The potential for using extracts of press residues from black, green, red, and white currants and from sea buckthorn berries as sources of antioxidants for foods use was investigated. Press residues were extracted with ethanol in four consecutive extractions, and total Folin-Ciocalteu $(\mathrm{F}-\mathrm{C})$ reactive material and authentic phenolic compounds were determined. Radical quenching capability and mechanisms were determined from total peroxyl radical-trapping antioxidant capacity (TRAP) and oxygen radical absorbance capacity (ORAC) assays and from diphenylpicrylhydrazyl (DPPH) kinetics, respectively; specific activities were normalized to $\mathrm{F}-\mathrm{C}$ reactive concentrations. Levels of total $\mathrm{F}-\mathrm{C}$ reactive materials in press residue extracts were higher than in many fruits and showed significant radical quenching activity. Black currant had the highest authentic phenol content and ORAC, TRAP, and DPPH reactivity. Sea buckthorn grown in northern Finland showed extremely high total specific DPPH reactivity. These results suggest that berry press residues offer attractive value-added products that can provide antioxidants for use in stabilizing and fortifying foods.

KEYWORDS: antioxidant activity/capacity, currants, DPPH, ORAC, phenolic compounds, press residue, sea buckthorn, TRAP

\section{INTRODUCTION}

Antioxidants are routinely added to foods to prevent oxidative degradation during processing and storage. Synthetic antioxidants such as butylated hydroxy toluene (BHT), butylated hydroxy anisole (BHA), tert-butylhydroquinone (TBHQ), and propyl gallate $(\mathrm{PG})$ have been used extensively in the food industry in the past, but concerns about their safety have increased interest in antioxidant compounds from natural sources, including tocopherols and tocotrienols, ascorbic acid, carotenoids, and a wide variety of phenolic compounds.

Interest in natural antioxidant compounds for foods has been intensified also by recognition that dietary antioxidants may provide multiple physiological protections. ${ }^{1,2}$ Information related to antimicrobial, anticarcinogenic, antiteratogenic, antiinflammatory, and antiallergenic properties of various classes of phenolic compounds has been accumulating progressively. ${ }^{3-6}$ Thus, there is a strong driving force to find useful sources of natural compounds for use as food antioxidants and as nutraceutical supplements.

At the same time, objections to using viable food supplies as sources for extracting and isolating food additives and nutraceuticals have raised interest in repurposing industrial food wastes to produce effective food-grade antioxidants. ${ }^{7}$ This not only preserves nutritious fruits and vegetables for direct consumption but also protects the environment, converts costly waste to value-added products, and contributes positively to economies.

Berries are a major source of antioxidants in Scandinavian diets. They are consumed whole (fresh and processed) and as juices. Press residues remaining after juicing are usually discarded. However, these materials still contain phenolic and other active compounds that may be usefully harvested and applied as value-added products (e.g., food antioxidants or nutritional supplements).

To assess whether berry press residues contain phenolic compounds at sufficient levels with good radical quenching activity to provide a potential industrial source for antioxidant compounds, press residues of Finnish currant and sea buckthorn berries were extracted in this study with ethanol. To keep the process food grade, no acid hydrolysis was performed. Radical scavenging activities ${ }^{8}$ and quenching mechanisms ${ }^{9}$ were evaluated by ORAC (oxygen radical absorbance capacity), TRAP (total peroxyl radical-trapping antioxidant capacity), and DPPH (diphenylpicrylhydrazyl) assays, and properties of the berry press residues were normalized to dry weight and phenolic content.

\section{MATERIALS AND METHODS}

2.1. Materials. 2.1.1. Berry Samples. Berries of Ribes nigrum (black currant 'Mortti' and green currant 'Vertti') and R. rubrum (red currant 'Red Dutch' and white currant 'White Dutch') were cultivated in Piikkiö at the Natural Resources Institute Finland $\left(22^{\circ} 33^{\prime}\right.$ E, $60^{\circ} 23^{\prime}$ $\mathrm{N}$, altitude 5-10 m). Berries of Hippophaë rhamnoides ssp. rhamnoides ('Tytti') were grown in sea buckthorn orchards of the Sammalmäki Sea Buckthorn Society in Turku (SB 1/south, $22^{\circ} 09^{\prime} \mathrm{E}, 60^{\circ} 23^{\prime} \mathrm{N}$, altitude $1 \mathrm{~m})$ and of the Kevo Subarctic Research Institute, University of Turku in Kittilä (SB 2/north, $24^{\circ} 37^{\prime} \mathrm{E}, 68^{\circ} 02^{\prime} \mathrm{N}$, altitude $210 \mathrm{~m}$ ). Optimally ripe berries, determined from color and taste by an

Received: January 12, 2018

Revised: March 12, 2018

Accepted: March 12, 2018

Published: March 12, 2018 
experienced orchardist, were randomly collected from several bushes of each variety and stored at $-20{ }^{\circ} \mathrm{C}$ until processed and analyzed.

2.1.2. Reagents. Reagents were purchased from the following sources: DPPH (2,2-diphenyl-1-picrylhydrazyl) and gallic acid from Eastman Organic Chemical (Rochester, NY); Folin-Ciocalteu phenol reagent, sodium carbonate $\left(\mathrm{Na}_{2} \mathrm{CO}_{3}\right)$, monopotassium phosphate $\left(\mathrm{KH}_{2} \mathrm{PO}_{4}\right)$, and dipotassium phosphate $\left(\mathrm{K}_{2} \mathrm{HPO}_{4}\right)$ from Merck (Darmstadt, Germany); AAPH (2,2-azobis(2-methyl-propionamidine) dihydrochloride, 97\%), Trolox (6-hydroxy-2,5,7,8-tetramethylchromane-2-carboxylic acid, 97\%), luminol (5-amino-2,3-dihydro-1,4phthalazinedione, $97 \%)$, sodium chloride $(\mathrm{NaCl})$, sodium hydroxide $(\mathrm{NaOH})$, fluorescein, 98\%, methanol (HPLC grade), and PVP (polyvinylpyrrolidone, ave mol wt 136000) from Sigma-Aldrich (St. Louis, $\mathrm{MO})$; boric acid $\left(\mathrm{H}_{3} \mathrm{BO}_{3}\right)$, monosodium phosphate $\left(\mathrm{NaH}_{2} \mathrm{PO}_{4}\right.$. $\left.\mathrm{H}_{2} \mathrm{O}\right)$, and disodium phosphate $\left(\mathrm{Na}_{2} \mathrm{HPO}_{4}\right)$ from J.T. Baker (Deventer, Holland); ethanol (Etax A, vol \% 96.1) from Altia Industrial (Rajamäki, Finland).

2.2. Methods. 2.2.1. Cold Pressing and Ethanol Extraction. Frozen berry samples of $200 \mathrm{~g}$ were thawed in a beaker in a microwave oven by treating twice for $1 \mathrm{~min}$ at power of $350 \mathrm{~W}$. The berries $\left(0{ }^{\circ} \mathrm{C}\right.$ $\pm 2{ }^{\circ} \mathrm{C}$ ) were pressed with a hydraulic press (Hafico, Fisher Maschinenfabrik GmbH, Germany) at a pressure of $200 \mathrm{~kg} / \mathrm{cm}^{2}$ through a stainless steel sieve coated with cheese cloth. Juice and the press cakes were frozen in plastic bags at $-20{ }^{\circ} \mathrm{C}$ until used, usually within 2 days. Press cakes of black currant, red currant, green currant, white currant, sea buckthorn 1 (south), and sea buckthorn 2 (north) were 22, 23, 20,25, 14, and $20 \%$ of the original berry weights, respectively.

Individual press cakes were thawed, weighed into beakers, and mixed with $92 \%$ ethanol in a ratio of $1: 2(\mathrm{w} / \mathrm{v})$. The ethanol was prepared by diluting Etax A (96.1 vol \% EtOH, Altia, Finland) with Milli-Q Plus (Merck Millipore, Darmstadt, Germany) $18 \mathrm{M} \Omega$ water. The resulting slurries were mixed with a magnetic stirrer for $30 \mathrm{~min}$ at room temperature protected from light with aluminum foil, then filtered with a Büchner funnel under vacuum. The first filtrates provided Extract 1; the residues then were re-extracted three more times in sequence with a constant volume of $92 \%$ ethanol to provide Extracts 2, 3, and 4.

2.2.2. Dry Solids Determination. Five-gram aliquots of press residues were weighed accurately on a watch-glass and dried overnight at $105^{\circ} \mathrm{C}$ until constant mass was reached. Samples were cooled for 10 min in a desiccator, then weighed to determine dry-weight and \% solids in the residues. Determinations were carried out in duplicates.

2.2.3. Determination of Folin-Ciocalteu-Reactive Compounds. The Folin-Ciocalteu $(\mathrm{F}-\mathrm{C})$ assay was applied to determine the total reducing capacity in the berry press residue extracts. The assay provides a quantitative measure of total phenolic compounds, but some nonphenolics such as vitamin $\mathrm{C}$, proteins, sugars, and metal ions are also $\mathrm{F}-\mathrm{C}$ reactive and these must be distinguished and accounted for in assay measurements.

Total $\mathrm{F}-\mathrm{C}$ reactive compounds in extracts were determined using a slightly modified micronized version of the Singleton-Rossi method. ${ }^{10,11}$ A $10 \mu \mathrm{L}$ aliquot of extract was mixed with $880 \mu \mathrm{L}$ of $0.2 \mathrm{~N} \mathrm{~F}-\mathrm{C}$ reagent in a $1 \mathrm{~mL} \mathrm{UV}$-vis semimicro cuvette and held for $5 \mathrm{~min}, 440 \mu \mathrm{L}$ of $20 \% \mathrm{Na}_{2} \mathrm{CO}_{3}$ was added, and the mixture was incubated for an additional $45 \mathrm{~min}$ to allow full reduction of the $\mathrm{F}-\mathrm{C}$ reagent. Absorbance was measured at $752 \mathrm{~nm}$ using a Varian Cary 50 Bio spectrophotometer (Agilent, Santa Clara, CA). Four dilutions were prepared for each berry extract and each of these was measured three times. Concentrations of total Folin-reactive substances were calculated by comparison of the measured absorbance to a standard curve prepared from gallic acid $(0.1,0.2,0.4,0.8$, and $1.6 \mathrm{mg} / \mathrm{mL})$ reacted under identical conditions. Absorbance of all the five gallic acid concentrations was determined in five parallel dilutions, each of which was tested three times, for a total of 15 measurements (Supplement Figure 1a). Concentrations of total Folin-reactive substances were expressed as gallic acid equivalents (GAE, $\mu \mathrm{mol} / \mathrm{mL}$ ) in nondiluted ethanol extracts, normalized to the wet and dry weights of press residues extracted, and converted to gallic acid equivalents expressed as $\mu \mathrm{mol} / \mathrm{g}$ fresh weight and as $\mu \mathrm{mol} / \mathrm{g}$ dry weight. During each working day with berry extracts, one dilution of each concentration of gallic acid was used to verify the standard curve.

To determine the content of nonphenolic $\mathrm{F}-\mathrm{C}$ reactive compounds in the extracts, $10 \mathrm{mg}$ of polyvinylpyrrolidone polymer (PVP) grains ${ }^{12}$ was added to $300 \mu \mathrm{L}$ of diluted extracts in test tubes, vortexed to disperse, and incubated for $0.5,1,2,3$, and $4 \mathrm{~h}$ and overnight. The tests were performed multiple times to ensure full reaction without degradation. During incubation, phenolic compounds bound to the PVP and subsequently were removed by centrifugation after incubation. The high mol wt PVP (mw 136000) does not bind proteins, acids, sugars, or other expected components of the extracts. Nonphenolics in the supernatants then were measured by the same F$\mathrm{C}$ reaction described for total $\mathrm{F}-\mathrm{C}$ reactive material. Three parallel samples were taken from each incubated extract and after reaction the absorbance of each sample was measured three times. Reactive nonphenolics in the supernatants were reported as gallic acid equivalents $(\mu \mathrm{mol} / \mathrm{mL})$ and converted to $\mu \mathrm{mol} / \mathrm{g}$ dry weight and $\mu \mathrm{mol} / \mathrm{g}$ fresh weight. Subtracting these values from corresponding values for total $\mathrm{F}-\mathrm{C}$ reactive compounds (previous paragraph) gives the content of authentic phenolic compounds in the extracts.

2.2.4. TRAP Analysis. A modified water-soluble TRAP (total peroxyl radical-trapping antioxidant potential) analysis used luminescence to measure antioxidant inhibition of luminol oxidation by free radicals generated from an azide initiator, AAPH. ${ }^{13}$

The luminol solution was prepared by dissolving $177 \mathrm{mg}$ of luminol in $5 \mathrm{~mL}$ of $1 \mathrm{~N} \mathrm{NaOH}$ and making up to $100 \mathrm{~mL}$ with $0.1 \mathrm{M}$ boric acid, $\mathrm{pH}$ 9. The solution was stored at $-20^{\circ} \mathrm{C}$ in $1 \mathrm{~mL}$ Eppendorf tubes until used. Dilutions of Trolox standard were prepared from 10 $\mathrm{mg} / \mathrm{mL}$ stock solutions dissolved in $92 \%$ EtOH. Berry extracts also were diluted in $92 \% \mathrm{EtOH}$. AAPH solution $(300 \mathrm{mM})$ in $0.1 \mathrm{M}$ phosphate-buffered saline $\left(\mathrm{Na}_{2} \mathrm{HPO}_{4}-\mathrm{NaH}_{2} \mathrm{PO}_{4}\right.$ in $0.9 \% \mathrm{NaCl}, \mathrm{pH}$ 7.4) was prepared fresh daily and held cold until use.

Optimum conditions for reaction time and response intensity were determined using dilutions of the first black currant extract. Accordingly, $225 \mu \mathrm{L}$ of $0.1 \mathrm{M}$ phosphate-buffered saline plus 12.5 $\mu \mathrm{L}$ of $10 \mathrm{mM}$ luminol and $10 \mu \mathrm{L}$ of either blank (92\% EtOH), Trolox standard, or a berry extract dilution were pipetted into individual wells of 96-well plates (White Cliniplate, Thermo Scientific, Vantaa, Finland) and warmed to $37{ }^{\circ} \mathrm{C}$. The reaction was started by adding to each well $50 \mu \mathrm{L}$ of $300 \mathrm{mM}$ AAPH solution in $0.1 \mathrm{M}$ phosphate buffer. Induction of luminol luminescence $(425 \mathrm{~nm})$ was followed for $50 \mathrm{~min}$ at $37^{\circ} \mathrm{C}$ in a BertholdTech Mithras LB 940 microplate reader (Berthold Technologies, Bad Wildbat, Germany) controlled by MicroWin 2000 software (Mikrotek Laborsysteme GmbH, Germany).

For all samples and standards, the half-time luminescence intensities $\left(t_{1 / 2}=t_{1 / 2 \text { sample }}-t_{1 / 2 \text { blank }}\right)$ were measured manually with the aid of minima and maxima of the sigmoidal luminescence curves (Supplement Figure 2a). Reaction inhibition by berry extracts, expressed as Trolox equivalents, was determined from Trolox standard curves (Supplement Figure 1b). Duplicate analyses of two parallel dilutions of the berry extracts were performed ( $n=4$ for each data point). Results were expressed as Trolox equivalents (TE) $\mu \mathrm{mol} / \mathrm{mL}$ of the nondiluted extract but also as $\mu \mathrm{mol} / \mathrm{g} \mathrm{FW}$ (fresh weight) and $\mu \mathrm{mol} /$ g DW (dry weight). Examples of TRAP data curves (from different dilutions of red currant extracts) are shown in Supplement Figure 3a.

2.2.5. ORAC Analysis. The water-soluble $\mathrm{ORAC}_{\mathrm{FL}}$ (oxygen radical absorbance capacity) measurement was carried out in black 96-well microplates with $\mu$ Clear bottom (Greiner Bio-One $\mathrm{GmbH}$, Frickenhausen, Germany). ${ }^{14}$ Reagents were $75 \mathrm{mM}$ potassium phosphate buffer ( $\mathrm{pH}$ 7.4), $0.09 \mu \mathrm{M}$ fluorescein (fresh solution in phosphate buffer prepared daily from frozen stock solutions), plus $399 \mathrm{mM}$ AAPH solution (also prepared daily), and Trolox standard solutions $(12.5 \mu \mathrm{M}-100 \mu \mathrm{M})$ in phosphate buffer.

Both ethanol and phosphate buffer were tested as solvents at different excitation and emission wavelengths. The best results were achieved in buffer with excitation at $485 \mathrm{~nm}$ and emission at $535 \mathrm{~nm}$. Extracts were tested at different dilutions to find concentrations that would yield a reaction time of about $20 \mathrm{~min}$ and not less than $10 \mathrm{~min}$. Net AUC calculations were made on sample dilutions giving reactivity midrange on the Trolox standard curve. 
Table 1. Yields of Berry Pressing, Dry Weight of Berry Press Residues, Total Phenolics, Nonphenolics, and Authentic Phenolics of the First Four Consecutive Ethanol Extracts of Berry Press Residues Expressed as Gallic Acid Equivalents (GAE) Normalized to Nondiluted Extracts and Press Residue Fresh Weights (FW)

\begin{tabular}{|c|c|c|c|c|c|c|c|c|c|}
\hline \multirow[b]{2}{*}{ berry } & \multicolumn{2}{|c|}{$\begin{array}{l}\text { after pressing of } 200 \mathrm{~g}(199.9 \pm 1.8) \\
\text { of berries }\end{array}$} & \multirow[b]{2}{*}{$\begin{array}{l}\text { press residue } \\
\text { extracts }\end{array}$} & \multicolumn{2}{|c|}{ total phenolics } & \multicolumn{2}{|c|}{ nonphenolics } & \multicolumn{2}{|c|}{$\begin{array}{l}\text { authentic phenolics } \\
\text { [tot phe. - non phe.] }\end{array}$} \\
\hline & $\begin{array}{l}\text { press residue, } \\
\mathrm{g} \text { (wet) }\end{array}$ & $\begin{array}{l}\text { press residue, dry } \\
\text { matter }(\%)\end{array}$ & & $\begin{array}{c}\mathrm{GAE}, \\
\mu \mathrm{mol} / \mathrm{mL}\end{array}$ & $\begin{array}{l}\text { GAE, } \mu \mathrm{mol} / \mathrm{g} \\
\text { FW }\end{array}$ & $\begin{array}{c}\mathrm{GAE} \\
\mu \mathrm{mol} / \mathrm{mL}\end{array}$ & $\begin{array}{c}\mathrm{GAE}, \\
\mu \mathrm{mol} / \mathrm{g} \mathrm{FW}\end{array}$ & $\begin{array}{c}\mathrm{GAE}, \\
\mu \mathrm{mol} / \mathrm{mL}\end{array}$ & $\begin{array}{c}\text { GAE, } \\
\mu \mathrm{mol} / \mathrm{g} \mathrm{FW}\end{array}$ \\
\hline \multirow[t]{4}{*}{ black currant } & \multirow[t]{4}{*}{43.1} & \multirow[t]{4}{*}{$41.6 \pm 0.1$} & I & $55.6 \pm 10.9$ & $55.3 \pm 10.8$ & $1.6 \pm 0.6$ & $1.5 \pm 0.5$ & 54.0 & 53.8 \\
\hline & & & II & $39.8 \pm 0.9$ & $58.7 \pm 1.3$ & $2.0 \pm 0.7$ & $2.9 \pm 1.0$ & 37.8 & 55.8 \\
\hline & & & III & $26.6 \pm 1.6$ & $13.8 \pm 0.8$ & $12.9 \pm 0.5$ & $6.7 \pm 0.3$ & 13.7 & 7.1 \\
\hline & & & IV & $6.1 \pm 0.6$ & $7.8 \pm 0.7$ & $0.0 \pm 0.0$ & $0.0 \pm 0.1$ & 6.1 & 7.8 \\
\hline \multirow[t]{4}{*}{ white currant } & \multirow[t]{4}{*}{49.1} & \multirow[t]{4}{*}{$30.5 \pm 0.8$} & I & $54.5 \pm 9.6$ & $24.7 \pm 4.4$ & $33.6 \pm 4.5$ & $15.3 \pm 2.1$ & 20.9 & 9.4 \\
\hline & & & II & $11.8 \pm 1.4$ & $9.7 \pm 1.2$ & $2.4 \pm 0.1$ & $2.0 \pm 0.1$ & 9.4 & 7.7 \\
\hline & & & III & $3.3 \pm 0.8$ & $5.1 \pm 1.3$ & $0.2 \pm 0.0$ & $0.3 \pm 0.0$ & 3.1 & 4.8 \\
\hline & & & IV & $1.8 \pm 0.4$ & $1.9 \pm 0.4$ & $0.1 \pm 0.0$ & $0.1 \pm 0.0$ & 1.7 & 1.8 \\
\hline \multirow[t]{4}{*}{ red currant } & \multirow[t]{4}{*}{45.2} & \multirow[t]{4}{*}{$31.1 \pm 0.0$} & I & $36.1 \pm 12.5$ & $20.5 \pm 7.1$ & $18.8 \pm 0.1$ & $10.6 \pm 0.1$ & 17.3 & 9.9 \\
\hline & & & II & $12.3 \pm 3.0$ & $11.9 \pm 2.9$ & $3.9 \pm 0.3$ & $3.8 \pm 0.3$ & 8.4 & 8.1 \\
\hline & & & III & $5.6 \pm 1.4$ & $5.6 \pm 1.4$ & $4.7 \pm 0.5$ & $4.7 \pm 0.5$ & 0.9 & 0.9 \\
\hline & & & IV & $1.6 \pm 0.2$ & $1.9 \pm 0.3$ & $0.0 \pm 0.0$ & $0.0 \pm 0.0$ & 1.6 & 1.9 \\
\hline \multirow[t]{4}{*}{ green currant } & \multirow[t]{4}{*}{39.2} & \multirow[t]{4}{*}{$34.7 \pm 0.3$} & I & $20.4 \pm 3.4$ & $17.1 \pm 2.9$ & $5.4 \pm 0.3$ & $4.5 \pm 0.3$ & 15.0 & 12.6 \\
\hline & & & II & $14.1 \pm 1.4$ & $8.1 \pm 0.8$ & $3.7 \pm 0.3$ & $2.1 \pm 0.2$ & 10.4 & 6.0 \\
\hline & & & III & $5.5 \pm 0.3$ & $3.9 \pm 0.2$ & $2.2 \pm 0.2$ & $1.6 \pm 0.2$ & 3.3 & 2.3 \\
\hline & & & IV & $1.2 \pm 0.1$ & $1.3 \pm 0.1$ & $0.6 \pm 0.0$ & $0.6 \pm 0.0$ & 0.6 & 0.7 \\
\hline \multirow{4}{*}{$\begin{array}{l}\text { sea buckthorn } 1 \\
\text { (south) }\end{array}$} & \multirow[t]{4}{*}{28.5} & \multirow[t]{4}{*}{$39.7 \pm 0.6$} & I & $6.4 \pm 0.4$ & $8.8 \pm 0.6$ & $3.0 \pm 0.2$ & $4.1 \pm 0.3$ & 3.4 & 4.7 \\
\hline & & & II & $3.0 \pm 0.3$ & $4.7 \pm 0.5$ & $1.4 \pm 0.1$ & $2.2 \pm 0.2$ & 1.6 & 2.5 \\
\hline & & & III & $1.7 \pm 0.2$ & $3.0 \pm 0.4$ & $0.7 \pm 0.1$ & $1.2 \pm 0.2$ & 1.0 & 1.8 \\
\hline & & & IV & $1.4 \pm 0.1$ & $2.5 \pm 0.1$ & $0.4 \pm 0.0$ & $0.8 \pm 0.1$ & 1.0 & 1.7 \\
\hline \multirow{4}{*}{$\begin{array}{l}\text { sea buckthorn } 2 \\
\text { (north) }\end{array}$} & \multirow[t]{4}{*}{40.1} & \multirow[t]{4}{*}{$33.9 \pm 0.5$} & I & $9.0 \pm 0.7$ & $13.6 \pm 1.1$ & $2.9 \pm 0.2$ & $4.3 \pm 0.3$ & 6.1 & 9.3 \\
\hline & & & II & $3.5 \pm 0.3$ & $7.2 \pm 0.6$ & $1.0 \pm 0.4$ & $2.1 \pm 0.8$ & 2.5 & 5.1 \\
\hline & & & III & $2.2 \pm 0.2$ & $4.2 \pm 0.4$ & $0.1 \pm 0.0$ & $0.2 \pm 0.1$ & 2.1 & 4.0 \\
\hline & & & IV & $1.6 \pm 0.2$ & $2.7 \pm 0.3$ & $0.1 \pm 0.0$ & $0.1 \pm 0.0$ & 1.5 & 2.6 \\
\hline
\end{tabular}

For reaction, phosphate buffer $(60 \mu \mathrm{L})$, fluorescein $(100 \mu \mathrm{L})$, and either blank, Trolox standard, or diluted berry extract $(20 \mu \mathrm{L})$ were pipetted into individual wells of a 96-well microplate. The reaction was started by pipetting $70 \mu \mathrm{L}$ of AAPH solution into the wells, and fluorescence (ex485, em $535 \mathrm{~nm}$ ) was recorded over time of $30 \mathrm{~min}$ using the Berthold Mithras LB 940 microplate reader described above. Areas under curves (AUC) were calculated with OriginLab 8.0 software (OriginLab Corporation, Northampton, MA); Net AUC values $=$ AUC standard or sample $-\mathrm{AUC}_{\text {blank }}$ (Supplement Figure $2 \mathrm{~b}$ ). Three parallel dilutions were prepared of each berry extract and two of each Trolox concentration and ORAC analyses were repeated three times on each. Net AUC values of the Trolox dilutions (100 $\mu \mathrm{M}, 50$ $\mu \mathrm{M}, 25 \mu \mathrm{M}$ and $12.5 \mu \mathrm{M}$ ) defined the standard curve (Supplement Figure 1c) and antioxidant values of the berry samples were calculated from the regression equation for this curve. Coefficient of determination $\left(R^{2}\right)$ of the standard curve ranged from 0.97 to 0.99 . Examples of ORAC reaction curves (different dilutions of black currant extracts) are shown in Supplement Figure 3b.

2.2.6. DPPH Analysis. Rates of extract reaction with DPPH were measured according to the method described by Xie and Schaich. ${ }^{15}$ The stock solution of DPPH (3.6 mg in $100 \mathrm{~mL}$ methanol) was diluted until the absorbance was close to one. The reagent bottle was kept in dark as covered with aluminum foil. Three milliliters of DPPH reagent was pipetted into a quartz cuvette and the starting absorbance at $515 \mathrm{~nm}$ was recorded. Thirty microliters of nondiluted sample was added and mixed quickly by aspiration, then recording of absorbance was started immediately and maintained for $10 \mathrm{~min}$ using a Varian Cary 50 Bio spectrophotometer. Reaction kinetics ( $\mu$ mols DPPH consumed/sec) were calculated from initial linear absorbance drop, usually within the first ten seconds, assuming an extinction coefficient of $10900 \mathrm{M}^{-1} \mathrm{~cm}^{-1}$, then normalized to phenol content of the extract to yield $\mu \mathrm{mols}$ DPPH consumed $/ \mu \mathrm{mol}$ phenol $/ \mathrm{sec}$.

The relative DPPH radical trapping capacity of each extract was calculated at $t_{30 \mathrm{~s}}, t_{1 \mathrm{~min}}, t_{2 \min }$ and $t_{10 \text { min }}$ (end of the reaction) according to $\% \mathrm{DPPH}=\left[\left(1-A_{\text {sample }} / A_{0}\right) \times 100\right]$ in which $A_{0}$ is the absorbance at $t_{0}$ and $A_{\text {sample }}$ is absorbance at a certain time point. Measurements of DPPH radical reaction kinetics of the ethanol blank and all the nondiluted berry extracts were repeated five times.

\section{RESULTS AND DISCUSSION}

3.1. Cold-Pressing and Ethanol Extraction. Table 1 shows the yields of the press residues of the six berry samples. The process simulates an industrial "Extra Virgin" juice extraction without enzymatic maceration of the berries. ${ }^{16}$ The high quantities of the press residues provide ample material for harvesting active compounds as a value-added product from the fruits. Pressing of sea buckthorn berries from South Finland gave the highest juice yield and the lowest amount of residue, while white currants gave the highest residual waste due to the viscous material and high proportion of seeds. The wet residues were $15-25 \%$ and dry residues were $10-20 \%$ of the original sample weight. Volumes of the 24 individual ethanol extracts varied significantly mainly due to varying viscosities of the samples, and usually the volumes of the first extracts were lower than the later ones.

3.2. Folin-Ciocalteu Reactive Compounds. Contents of total $\mathrm{F}-\mathrm{C}$ reactive materials, nonphenolic components, and authentic phenolics in the berry press cakes are listed in Table 1. Summed over four extracts, black currants (BC) had the highest total Folin-reactive GAE values among all the berries, with $326 \mu \mathrm{mol} \mathrm{GAE} / \mathrm{g} \mathrm{dw}$. Interestingly, nearly all of this was authentic phenolics, with $<10 \%$ nonphenolic reactive compounds. Total $\mathrm{F}-\mathrm{C}$ reactive compounds were $40-50 \%$ lower in white currants and red currants (136 and $128 \mu \mathrm{mol} \mathrm{GAE} / \mathrm{g} \mathrm{dw}$, respectively), and here nonphenolic compounds contributed 

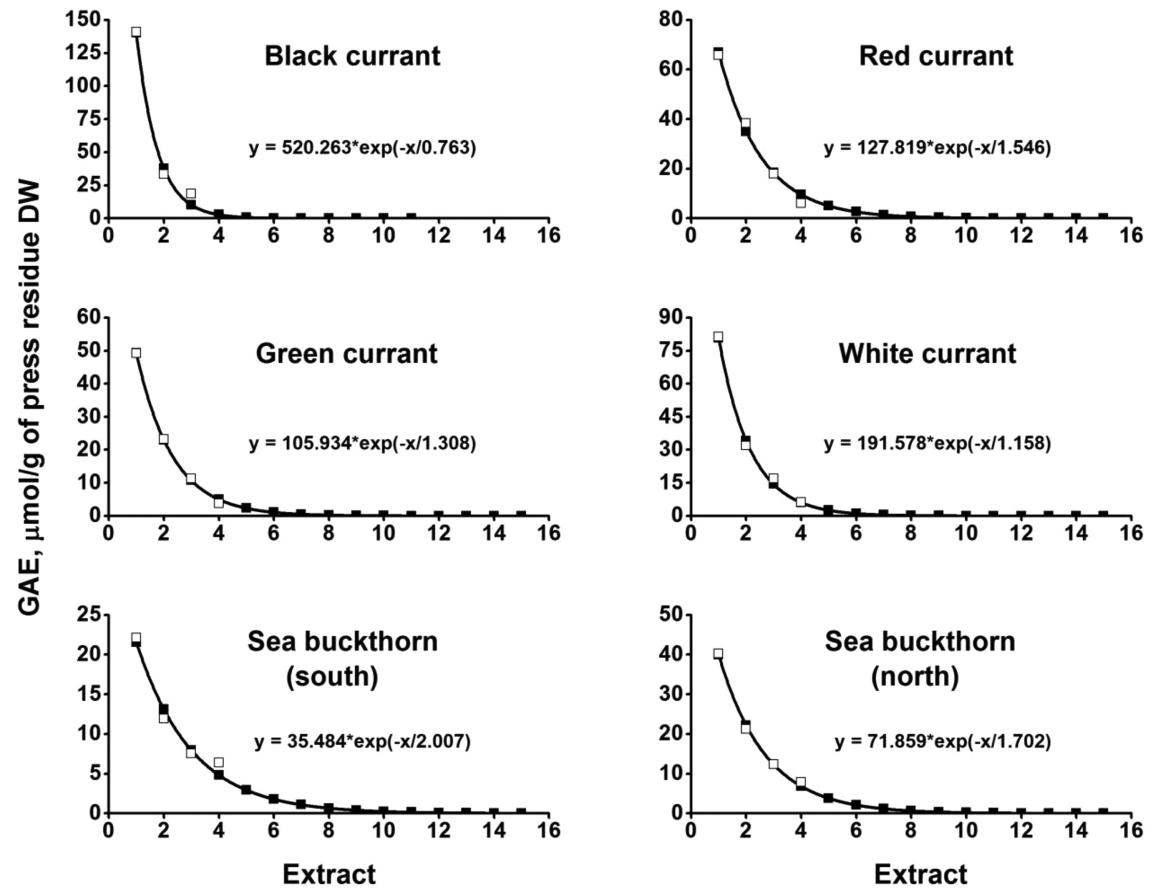

Figure 1. F-C reactive materials removed in sequential extractions of berry press residues. Fitted measured values (white square symbols) and 15 calculated residual values (black square symbols).

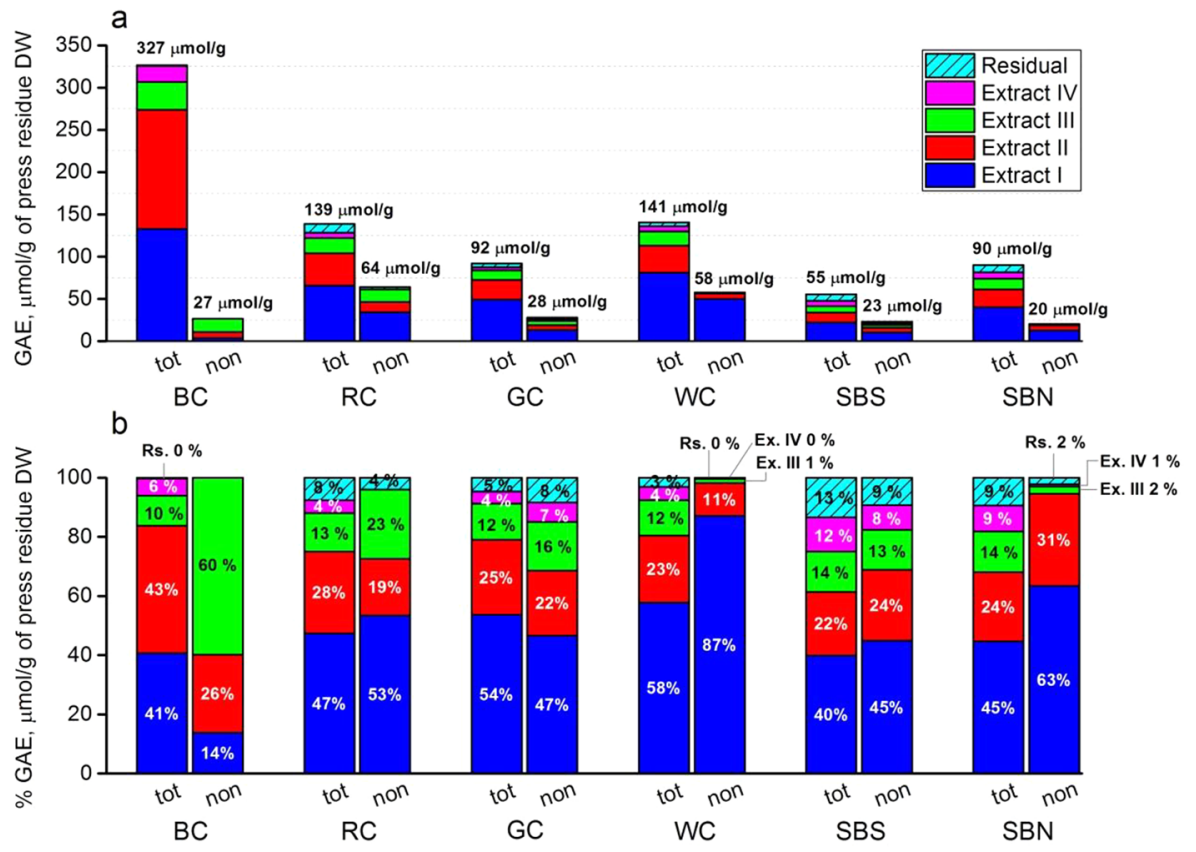

Figure 2. Bar chart of the total phenolic (tot) and nonphenolic (non) compounds of the berry press residues determined by the Folin-Ciocalteu method and expressed as gallic acid equivalents (GAE) $\mu \mathrm{mol} / \mathrm{g}$ DW (a). Relative gallic acid equivalents of the berry press residue extracts (b). The residual contents were estimated by the descending curve $\left(y=A_{1} \times \exp \left(-x / t_{1}\right)+y_{0}\right)$ approaching asymptotically the content zero. $\mathrm{BC}=\mathrm{black}$ currant, $\mathrm{RC}=$ red currant, $\mathrm{GC}=$ green currant, $\mathrm{WC}=$ white currant, $\mathrm{SBS}=$ sea buckthorn south, and $\mathrm{SBN}=$ sea buckthorn north.

half or more of the total reactivity. Green currants $(87 \mu \mathrm{mol}$ $\mathrm{GAE} / \mathrm{g} \mathrm{dw}$ ) and sea buckthorns (48 and $82 \mu \mathrm{mol} \mathrm{GAE} / \mathrm{g} \mathrm{dw}$ ) had the lowest total GAE values, with $30-50 \%$ of the reactivity from nonphenolics. Whether taken as total $\mathrm{F}-\mathrm{C}$ reactive material or authentic phenolics, these values in berry press cakes, material normally discarded, compare quite favorably to or even exceed phenol contents of a wide range of other fruits (7.5-159 $\mu \mathrm{mol} / \mathrm{g}$ dry wt for 20 fruits $^{17}$ or $1-35 \mu \mathrm{mol} / \mathrm{g}$ fresh weight for 62 fruits $^{18}$ ). High $\mathrm{F}-\mathrm{C}$ reactive compounds together with ample supply of material make press cakes from these five berries (particularly red, black, and white currants) quite attractive as potential sources of antioxidants for food or supplement applications.

The majority of both the phenolic and nonphenolic $\mathrm{F}-\mathrm{C}$ reactive compounds were dissolved typically in the first few extracts, effective enough for practical extractions. As expected, 
Table 2. Antioxidant Activities of Berry Residues Defined with TRAP and ORAC Method ${ }^{a}$

\begin{tabular}{|c|c|c|c|c|c|c|c|c|c|}
\hline \multirow{2}{*}{\multicolumn{2}{|c|}{ berry press }} & \multicolumn{4}{|c|}{ TRAP } & \multicolumn{4}{|c|}{ ORAC } \\
\hline & & \multirow{2}{*}{$\begin{array}{c}\mathrm{TE}, \\
\mu \mathrm{mol} / \mathrm{mL} \\
25.9 \pm 6.3\end{array}$} & \multirow{2}{*}{$\begin{array}{c}\text { TE, } \mu \mathrm{mol} / \mathrm{g} \\
\text { FW } \\
25.7 \pm 6.3\end{array}$} & \multirow{2}{*}{$\begin{array}{c}\mathrm{TE}, \mu \mathrm{mol} / \mu \mathrm{mol} \\
\text { total phenolics } \\
0.46\end{array}$} & \multirow{2}{*}{$\begin{array}{c}\mathrm{TE}, \mu \mathrm{mol} / \mu \mathrm{mol} \\
\text { authentic } \\
\text { phenolics } \\
0.48\end{array}$} & \multirow{2}{*}{$\begin{array}{c}\mathrm{TE} \\
\mu \mathrm{mol} / \mathrm{mL} \\
89.4 \pm 18.5\end{array}$} & \multirow{2}{*}{$\begin{array}{c}\text { TE, } \mu \mathrm{mol} / \mathrm{g} \\
\text { FW } \\
88.8 \pm 18.3\end{array}$} & \multirow{2}{*}{$\begin{array}{c}\mathrm{TE}, \mu \mathrm{mol} / \mu \mathrm{mol} \\
\text { total phenolics } \\
1.61\end{array}$} & \multirow{2}{*}{$\begin{array}{c}\text { TE, } \mu \mathrm{mol} / \mu \mathrm{mol} \\
\text { authentic } \\
\text { phenolics } \\
1.65\end{array}$} \\
\hline black currant & I & & & & & & & & \\
\hline & II & $14.2 \pm 1.2$ & $21.0 \pm 1.8$ & 0.36 & 0.38 & $57.9 \pm 7.4$ & $85.4 \pm 9.2$ & 1.45 & 1.53 \\
\hline & III & $8.7 \pm 1.0$ & $4.5 \pm 0.5$ & 0.33 & 0.63 & $46.1 \pm 3.8$ & $24.0 \pm 2.0$ & 1.74 & 3.38 \\
\hline & IV & $1.6 \pm 0.1$ & $2.0 \pm 0.2$ & 0.26 & 0.26 & $17.0 \pm 2.1$ & $21.6 \pm 2.7$ & 2.77 & 2.77 \\
\hline \multirow[t]{4}{*}{ red currant } & I & $20.4 \pm 1.7$ & $11.6 \pm 1.0$ & 0.57 & 1.17 & $40.5 \pm 13.2$ & $23.0 \pm 7.5$ & 1.12 & 2.32 \\
\hline & II & $6.7 \pm 0.4$ & $6.4 \pm 0.4$ & 0.54 & 0.79 & $15.6 \pm 4.8$ & $15.1 \pm 2.3$ & 1.27 & 1.86 \\
\hline & III & $4.0 \pm 0.1$ & $3.9 \pm 0.1$ & 0.70 & 4.33 & $9.1 \pm 1.7$ & $9.0 \pm 1.7$ & 1.61 & 10.00 \\
\hline & IV & $0.8 \pm 0.1$ & $1.0 \pm 0.1$ & 0.53 & 0.53 & $4.1 \pm 1.2$ & $4.7 \pm 1.4$ & 2.47 & 2.47 \\
\hline \multirow[t]{4}{*}{ green currant } & I & $10.4 \pm 1.9$ & $8.7 \pm 1.6$ & 0.51 & 0.69 & $39.2 \pm 5.4$ & $32.9 \pm 4.5$ & 1.92 & 2.61 \\
\hline & II & $6.5 \pm 0.2$ & $3.7 \pm 0.1$ & 0.46 & 0.62 & $21.0 \pm 5.1$ & $12.1 \pm 2.6$ & 1.49 & 2.02 \\
\hline & III & $1.8 \pm 0.0$ & $1.3 \pm 0.0$ & 0.33 & 0.57 & $10.4 \pm 1.5$ & $7.4 \pm 1.1$ & 1.90 & 3.22 \\
\hline & IV & $1.0 \pm 0.2$ & $1.1 \pm 0.2$ & 0.85 & 1.57 & $6.8 \pm 0.6$ & $6.4 \pm 2.9$ & 4.92 & 9.14 \\
\hline \multirow[t]{4}{*}{ white currant } & I & $18.5 \pm 1.9$ & $8.4 \pm 0.9$ & 0.34 & 0.89 & $36.9 \pm 6.8$ & $16.8 \pm 3.1$ & 0.68 & 1.79 \\
\hline & II & $7.7 \pm 0.7$ & $6.4 \pm 0.6$ & 0.66 & 0.83 & $6.0 \pm 2.1$ & $5.0 \pm 1.7$ & 0.52 & 0.65 \\
\hline & III & $1.6 \pm 0.1$ & $2.5 \pm 0.1$ & 0.49 & 0.52 & $4.7 \pm 1.1$ & $7.2 \pm 1.6$ & 1.41 & 1.50 \\
\hline & IV & $0.6 \pm 0.0$ & $0.6 \pm 0.0$ & 0.32 & 0.33 & $4.4 \pm 0.4$ & $4.8 \pm 0.4$ & 2.53 & 2.67 \\
\hline \multirow{4}{*}{$\begin{array}{l}\text { sea buckthorn } \\
1 \text { (south) }\end{array}$} & I & $2.4 \pm 0.3$ & $3.3 \pm 0.5$ & 0.38 & 0.70 & $11.4 \pm 4.8$ & $15.7 \pm 6.7$ & 1.78 & 3.34 \\
\hline & II & $1.3 \pm 0.2$ & $2.0 \pm 0.3$ & 0.43 & 0.80 & $6.3 \pm 3.5$ & $9.9 \pm 5.6$ & 2.11 & 3.96 \\
\hline & III & $0.4 \pm 0.1$ & $0.6 \pm 0.1$ & 0.20 & 0.33 & $4.6 \pm 2.2$ & $8.0 \pm 3.9$ & 2.67 & 4.44 \\
\hline & IV & $0.1 \pm 0.0$ & $0.3 \pm 0.0$ & 0.12 & 0.18 & $4.6 \pm 1.7$ & $8.3 \pm 3.1$ & 3.32 & 4.88 \\
\hline \multirow{4}{*}{$\begin{array}{l}\text { sea buckthorn } \\
2 \text { (north) }\end{array}$} & I & $3.7 \pm 0.4$ & $5.6 \pm 0.6$ & 0.41 & 0.60 & $20.3 \pm 4.1$ & $30.7 \pm 6.2$ & 2.26 & 3.30 \\
\hline & II & $2.2 \pm 0.2$ & $4.6 \pm 0.4$ & 0.64 & 0.90 & $11.4 \pm 4.1$ & $23.3 \pm 8.4$ & 3.24 & 4.57 \\
\hline & III & $1.3 \pm 0.1$ & $2.6 \pm 0.2$ & 0.62 & 0.65 & $11.2 \pm 2.1$ & $21.7 \pm 4.1$ & 5.17 & 5.43 \\
\hline & IV & $0.8 \pm 0.1$ & $1.4 \pm 0.1$ & 0.52 & 0.54 & $9.6 \pm 4.0$ & $16.3 \pm 6.8$ & 6.04 & 6.27 \\
\hline
\end{tabular}

${ }^{a}$ Results are expressed as Trolox equivalents (TE) $\mu \mathrm{mol} / \mathrm{mL}$ of the nondiluted ethanol extracts and as $\mu \mathrm{mol} / \mathrm{g}$ in press residues (FW), and normalized to the total phenolic and authentic phenolic values $(\mu \mathrm{mol} / \mathrm{g} \mathrm{FW})$.
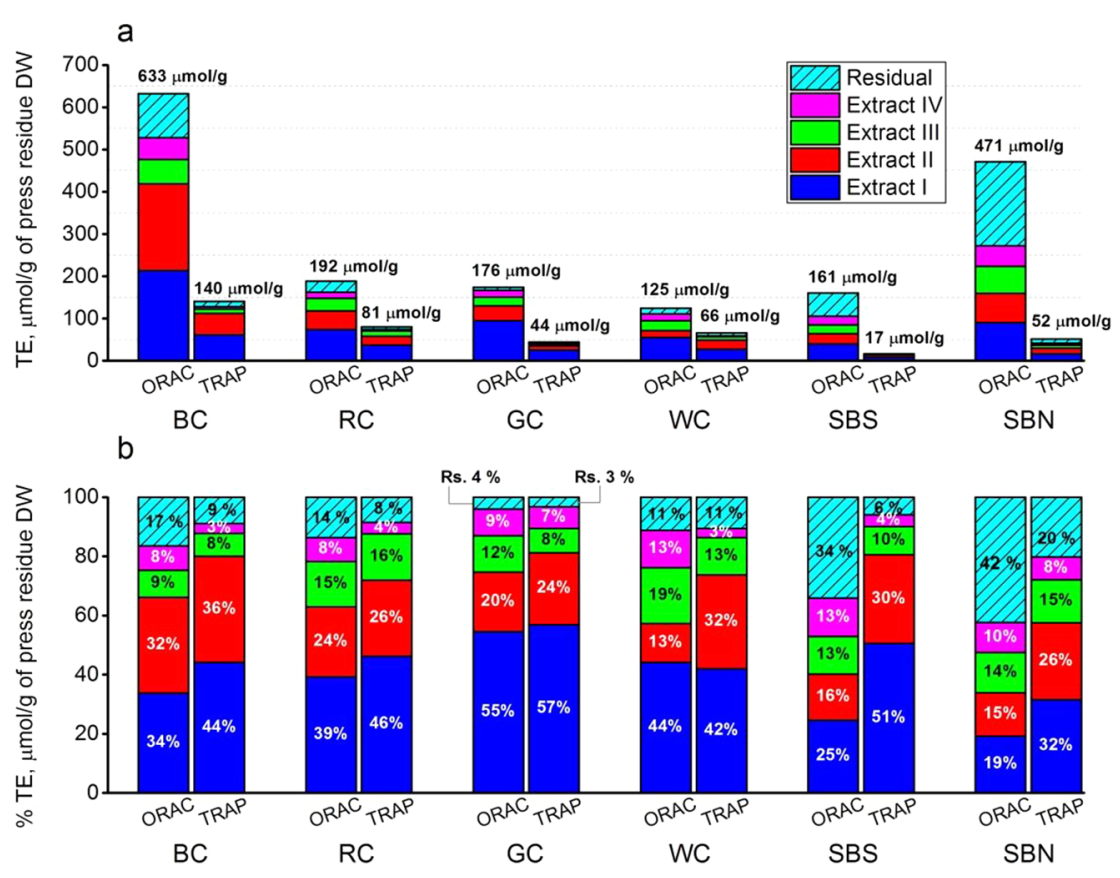

Figure 3. Bar chart of ORAC and TRAP analyses of the extracts of the berry press residues expressed as Trolox equivalents (TE) $\mu \mathrm{mol} / \mathrm{g}$ DW (a). Relative Trolox equivalents of the berry press residue extracts (b).

the amounts removed in subsequent extractions decreased exponentially. It is not known yet how extracted compounds change with extraction number. Extraction is driven by both solubility and movement of material to the surface for removal. In the first extraction, the highest amount of material is available so the most soluble and accessible compounds are dissolved until the solubility limit of ethanol is reached. In the second extract, some less soluble compounds may be dissolved. More compounds are dissolved also by a combination of ethanol penetrating to underlying layers to dissolve compounds 
Table 3. Initial Reaction Rates with $\mathrm{DPPH}^{\bullet}$ Radicals and Total Trapping Capacity (\%) of Berry Press Residues at Different Time Points

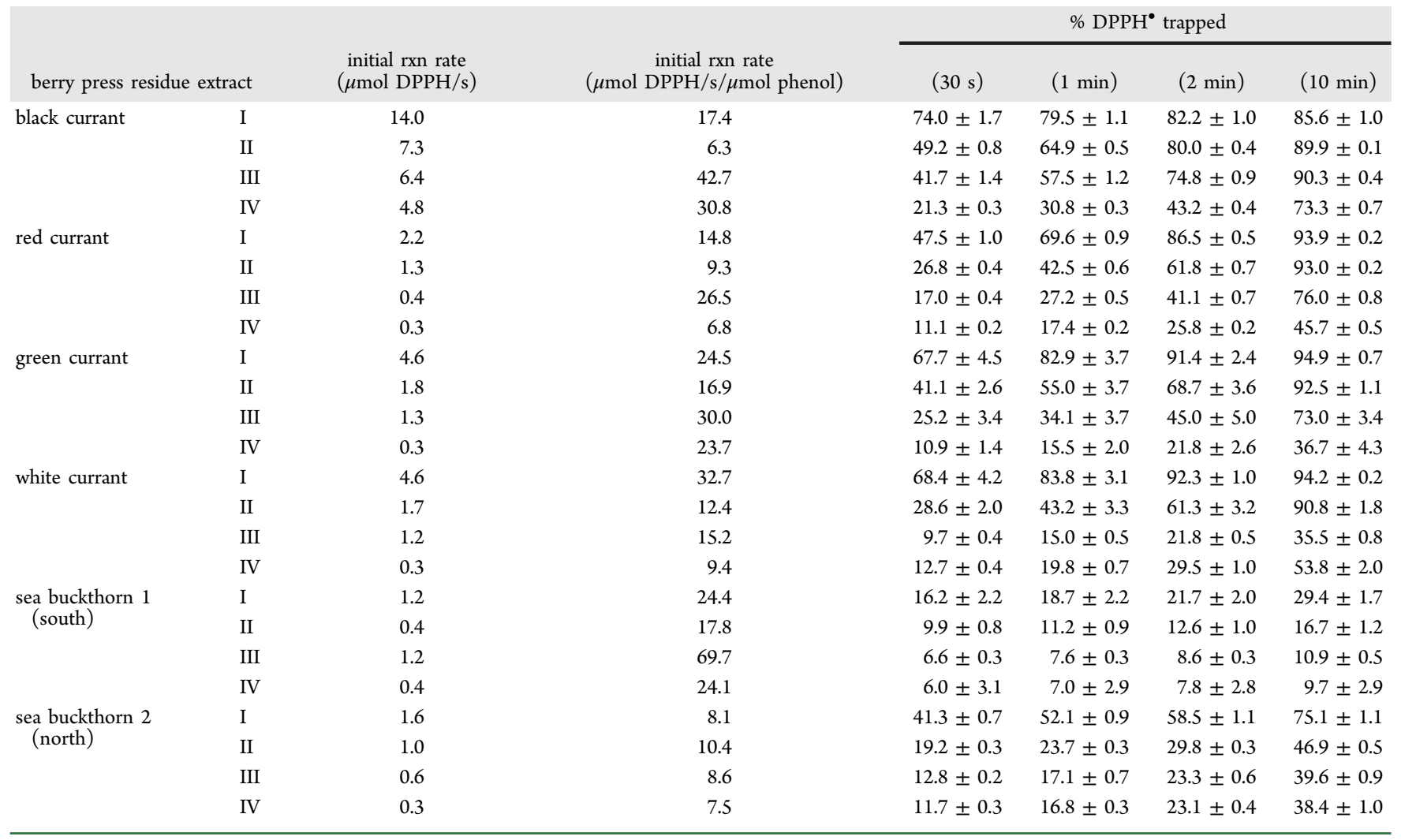

not previously reached, plus compounds migrating from underlying layers to the surface as compounds in outer layers are removed. This process continues with successive extractions until no soluble or migrating compounds are present. The fact that radical quenching per mol of phenolic compounds changed in each extract, in some cases even increasing with extraction number, indicates that different compounds were present in each extract and supports contributions of both solubility and migration to extraction. We do not expect that ethanol can extract high polymers of phenolic compounds that are highly bound to proteins or other macromolecule without additional treatments, e.g. acid hydrolysis

To define the total amount of $\mathrm{F}-\mathrm{C}$ reactive compounds in the berry press residues, the residual unextracted $\mathrm{F}-\mathrm{C}$ reactive compounds were estimated from the descending curve $\left(y=A_{1}\right.$ $\left.\times \exp \left(-x / t_{1}\right)+y_{0}\right)$ approaching asymptotically the content zero, as defined by the first four extracts (Figure 1). The theoretical values were calculated on 15 consecutive extractions and the sum was regarded to represent the $100 \%$ yield. The results are shown in Table 1 and displayed also in Figure 2a. Figure $2 \mathrm{~b}$ reveals the relative proportion of each extract of the total gallic acid equivalents within each berry press residue. The same approach was used to determine the $100 \%$ levels for $\mathrm{F}-\mathrm{C}$, TRAP, and ORAC values.

3.3. TRAP Analyses. TRAP results for sequential extracts of berry press residues varied with both variety and extract number, as summarized in Table 2 and visualized in Figures 3a and b. Extracts from black currant press residues showed the highest reactivity with peroxyl radicals among all the samples, and extracts of sea buckthorn residues from South Finland showed the lowest. Press residue extracts from sea buckthorn berries grown in North Finland had more than three times the antioxidant capacity of press residues from the southern berries. Press residue extracts from red currants and white currants showed equal TRAP potential. This order of reactivity parallels phenol contents of the various berry press residues.

The activity of the two first extractions varied widely between $50 \%$ and $90 \%$ of the total TRAP values. TRAP values then decreased with each successive extraction, which was to be expected since the yields of phenolic compounds also dropped. However, normalization of the values to the amount of total phenolics and authentic phenolics in each extract showed that radical scavenging activity was for the most part retained or even increased in later extractions (Table 2).

The calculated residual TRAP values were highly dependent on the berry samples. Typically the residual value after four extractions was less than $10 \%$, but ranged as high as one-fourth of the total Trolox equivalents in northern sea buckthorn berries (Table 2).

This supports, once again, differences in phenolic contents of the berries and indicates that substantial antioxidant potential can remain unextracted by current conditions that were deliberately mild to keep extracts food-grade. Since insoluble bound and polymeric phenolic compounds are certainly present in press residues, experimentation with food-grade acid hydrolysis may increase yields of antioxidant material.

3.4. ORAC Analyses. ORAC values of the berry extracts as Trolox equivalents $(\mu \mathrm{mol} / \mathrm{mL}, \mu \mathrm{mol} / \mathrm{g} \mathrm{FW}, \mu \mathrm{mol} / \mathrm{g} \mathrm{DW})$ are presented in Table 2 and in Figure $3 a$ and b. Black currant showed, again, the highest antioxidant capacity while the ORAC values of the southern sea buckthorn and white currant extracts were the lowest of all the berries. As with TRAP, ORAC activities decreased in successive extracts of each berry press residue due to lower amounts of material extracted. 
However, normalization to phenolic content of each extract showed that specific radical quenching capabilities by $\mathrm{H}$ atom transfer (i.e., moles AAPH quenched per mole phenolic compounds) were retained or even increased in whatever phenolic compounds were recovered in the successive extractions. Amounts of the remaining, calculated residual ORAC-active compounds, measured as Trolox equivalents, were typically higher than the corresponding residuals in TRAP-analyses (Figure 3b). More detailed information of the reactive compounds is required to reveal the structural basis for differences between TRAP and ORAC analyses.

3.5. DPPH Analysis. DPPH reaction curves for extracts of berry press residues are shown in Supplement Figure 4, and the initial reaction rates and DPPH radical quenching efficiencies of the berry press residue extracts are presented in Table 3. Overall, $\mathrm{DPPH}^{\bullet}$ quenching was fastest and greatest in black currants followed by white, green, and red currants. Extracts from Sea buckthorn 1 grown in South Finland showed very low reactivity with $\mathrm{DPPH}^{\circ}$. As with the other antioxidant assays, nominal rates and quenching capacities both decreased with successive extractions, but normalization to phenol contents of each extract showed that this resulted from lower phenol contents and activity per molecule of phenol are largely retained or even increased.

Shapes of the DPPH reaction curves indicate marked differences in types of phenolic compounds present in the extracts. According to Brand-Williams, Cuvelier, and Berset, ${ }^{19}$ who modified the method of Blois, ${ }^{20}$ the DPPH reaction can be rapid, intermediate, or slow. Xie and Schaich found that reactions of 25 different antioxidant compounds with $\mathrm{DPPH}^{\bullet}$ fell into five groups according to kinetics: instantaneous (1), very fast (2), moderate (3), slow (4), and no reaction (5). ${ }^{15}$ The initial velocity of the reaction revealed the quenching mechanism: initial reactions faster than $30 \mathrm{~s}$ are mainly based on the ET (electron transfer) mechanism, reactions with substantial drop in absorbance but occurring more slowly were most likely electron transfer dominant but with steric hindrance, while those with very slow reaction occur by HAT (hydrogen atom transfer).

Using results of Xie and Schaich as a guide, ${ }^{15}$ only the first extract of black currants and to a lesser extent the other currants give clear evidence for small molecules acting by electron transfer. Second extracts from currant still suggest electron transfer but from larger sterically hindered molecules. Reactions of the third and fourth extracts from currants are slower and may result from very hindered electron transfer or from slow $\mathrm{H}$ atom transfer. The first extract from sea buckthorn 2 suggests hindered electron transfer; all other curves from sea buckthorn extracts are more typical of slower $\mathrm{H}$ atom transfer.

The effects of electron versus $\mathrm{H}$ atom transfers are evident in the differences between relative initial reaction rates and reaction stoichiometries calculated after longer reaction times.

Fast reacting electron transfers are most relevant to efficient quenching of radicals with short half-lives such as $\mathrm{HO}^{\bullet}$ and lipid radicals. Normalized reaction rates indicate that each extract from all the berry press cake residues has some fast reacting components with reasonably comparable rates. Ascorbic acid is one compound that reduces DPPH radical very rapidly and should be expected in press cake residues. At the same time, slower hindered electron transfer and $\mathrm{H}$ atom transfer allowed total radical quenching to accumulate over time. In this case, normalized stoichiometries (mol DPPH consumed/mol phenol as GAE equivalents) increased with reaction time and with extraction number, and values varied notably among the berry residue extracts. Higher stoichiometries are consistent with higher contents of larger polyphenols or soluble polymeric phenolics rather than simple phenolic compouds like phenolic acids.

3.6. Compositional Background of Berries Investigated. Identifying individual phenolic components of the press residue extracts was beyond the scope of this study which focused on determining whether the press residues yielded sufficient material with antioxidant activity to warrant further analyses. Nevertheless, differences between the dominant classed of phenolic compounds in currants and sea buckthorn berries determined in our previous work ${ }^{21-30}$ can provide insights to help explain the antioxidant behavior observed in this study. Assuming that the press cake extracts contain phenolic compositions comparable to those of the respective berries, the shift between dominant classes of phenolic compounds in different currants can explain most of their variations in radical reactivity.

The phenolic contents of currants, the first four varieties investigated in this study, are known to be a very complex mixture of anthocyanins, flavonol glycosides, flavan-3-ols, ellagitannins, proanthocyanidins, and phenolic acid derivatives. ${ }^{21}$ Anthocyanins of black currant "Mortti" comprised close to $90 \%$ of total phenolic compounds with the main forms being mainly delphinidin 3-O-rutinoside (32\% of Tot-Ph), delphinidin 3-O-glucoside (22\%), cyanidin 3-O-rutinoside (26\%), and cyaniding-3-O-glucoside (6\%). Small amounts of $p$-coumaric acid derivatives and flavonol glycosides were also found. Press residue of "Mortti" has been successfully used as raw material for extrusion test products. ${ }^{31}$ The high concentrations of anthocyanins are probably major contributors to the strong radical quenching activity of black currant press residue extracts.

Green currant variety "Vertti", also belonging to the species $R$. nigrum, contains no anthocyanins but glycosides of phenolic acids account for over half of the total phenolics, with caffeic acid-hexosides, coumaroylquinic acid-hexosides, and vanillic acid-hexoside as the major compounds. None of the phenolic acids has radical quenching capabilities as strong as anthocyanins, the main phenolic compounds in black currants. $(+)$-Catechin is the main flavan-3-ol and (-)-epicatechin the minor one. Quercetin 3-O-rutinoside, 3-O-glucoside, and 3-O$\left(6^{\prime \prime}\right.$-malonyl)-glucoside, the three primary flavonol derivatives in "Vertti", 21 are strong radical quenchers.

"Red Dutch" and "White Dutch" currants, both R. rubrum species, are low in total phenolics with levels only around 30 $\mathrm{mg} / 100 \mathrm{~g}$ fresh berries. ${ }^{21}$ Caffeic acid-hexosides, coumaroylquinic acid-hexosides, and vanillic acid-hexosides comprise together about $40 \%$ and glycosylated flavonols about $10 \%$ of total phenolics in the berries. Cyanidin glycosides represent close to one-third of phenolic compounds in red currants but white currants contain no anthocyanins.

For sea buckthorn berries of the varieties "Tytti" and "Terhi", our earlier investigations showed isorhamnetin and quercetin glycosides to be the major flavonol derivatives $(\sim 100 \mathrm{mg} / 100 \mathrm{~g}$ fresh weight), reaching slightly higher levels in North than in South Finland. ${ }^{21,23}$ Further, the total amount of proanthocyanidins in Finnish sea buckthorns grown in North Finland was shown to reach $1-2 \%$ of dry weight of the berries, whereas the compounds in South Finland are typically less than half of that. $^{22,24}$ Quercetin probably is responsible for DPPH radical quenching in early extracts, while the soluble proanthocyanidins 
with many phenol groups per molecule are most likely components of later extracts and contribute to prolonged reactions and high specific activity.

The content and activity of phenolic compounds isolated from press residues of these berries suggests that the wastes can be potential useful sources of food and nutraceutical antioxidants. The next steps will be to identify the antioxidant compounds present and compare them with the berry and juice contents noted above. The stage of ripeness, ${ }^{32}$ type of byproduct, ${ }^{7}$ and various technological modifications ${ }^{33}$ will be particularly important when optimizing extracts for possible food and nutraceutical applications.

\section{ASSOCIATED CONTENT}

\section{S Supporting Information}

The Supporting Information is available free of charge on the ACS Publications website at DOI: 10.1021/acs.jafc.8b00177.

Standard curves: gallic acid, Folin-Ciocalteu assay; Trolox, DPPH, and ORAC assays (PDF)

TRAP luminescence curves, ORAC net area under curve (PDF)

Typical reaction curves: TRAP, ORAC (PDF)

$\mathrm{DPPH}$ kinetic reaction curves (PDF)

\section{AUTHOR INFORMATION}

\section{Corresponding Author}

*E-mail: heikki.kallio@utu.fi. Phone: +358 2 3336870. Fax: +35829450 5040 .

\section{ORCID 1}

Heikki P. Kallio: 0000-0001-6579-7063

Karen M. Schaich: 0000-0003-3262-5438

Jukka-Pekka Suomela: 0000-0001-6118-9589

\section{Funding}

This study was supported by Tekes, the Finnish Funding Agency for Innovation and Finnish companies as part of the project "Finnish-Indian Ingredients for Improving Food Safety and Health" (Decision No. 40055/13). Partial support was also provided by USDA National Institute of Food and Agriculture Hatch Project No. 183471 through the New Jersey Agricultural Experiment Station, Hatch Project No. NJ10134.

\section{Notes}

The authors declare no competing financial interest.

\section{REFERENCES}

(1) Galvano, F.; La Fauci, L.; Lazzarino, G.; Fogliano, V.; Ritieni, A.; Ciappellano, S.; Battistini, N. C.; Tavazzi, B.; Galvano, G. Cyanidins: metabolism and biological properties. J. Nutr. Biochem. 2004, 15, 211.

(2) Boots, A. W.; Haenen, G. R. M. M.; Bast, A. Health effects of quercetin: From antioxidant to nutraceutical. Eur. J. Pharmacol. 2008, $585,325-337$.

(3) Arts, I. C. W.; Hollman, P. C. H. Polyphenols and disease risk in epidemiologic studies. Am. J. Clin. Nutr. 2005, 81, 317S-325S.

(4) Kris-Etherton, P. M.; Lefevre, M.; Beecher, G. R.; Gross, M. D.; Keen, C. L.; Etherton, T. D. Bioactive compounds in nutrition and health-research methodologies for establishing biological function: the antioxidant and anti-inflammatory effects of flavonoids on atherosclerosis. Annu. Rev. Nutr. 2004, 24, 511-538.

(5) Middleton, E., Jr.; Kandaswami, C.; Theoharides, T. C. The effects of plant flavonoids on mammalian cells: implication for inflammations, heart disease and cancer. Pharmacol. Rev. 2008, 52, $673-751$.
(6) Williamson, G.; Manach, C. Bioavailability and bioefficacy of polyphenols in humans. II. Review of 93 intervention studies. Am. J. Clin. Nutr. 2005, 81, 243S-255S.

(7) Ambigaipalan, P.; de Camargo, A. C.; Shahidi, F. Phenolic compounds of pomegranate byproducts (outer skin, mesocarp, divider membrane) and their antioxidant activities. J. Agric. Food Chem. 2016, 64, 6584-6604.

(8) Prior, R. L.; Wu, X.; Schaich, K. M. Standard methods for the determination of antioxidant capacity and phenolics in foods and dietary supplements. J. Agric. Food Chem. 2005, 53, 4290-4302.

(9) Schaich, K. M.; Tian, X.; Xie, J. Hurdles and pitfalls in measuring antioxidant efficacy: A critical evaluation of ABTS, DPPH, and ORAC assays. J. Funct. Foods 2015, 14, 111-125.

(10) Singleton, V. L.; Rossi, J. A. Colorimetry of total phenolics with phosphomolybdic-phosphotungstic acid reagents. Am. J. Enol. Vitic. $1965,16,144-158$.

(11) Singleton, V. L.; Orthofer, R.; Lamuela-Raventós, R. M. Analysis of total phenols and other oxidation substrates and antioxidants by means of Folin-Ciocalteu reagent. Methods Enzymol. 1999, 299, 152178.

(12) Agbor, G. A.; Vinson, J. A.; Donnelly, P. E. Folin-Ciocalteu reagent for polyphenolic assay. Int. J. Food Sci. Nutr Diet 2014, 3, 147156.

(13) Alanko, J.; Riutta, A.; Mucha, I.; Vapaatalo, H.; Metsä-Ketelä, T. Modulation of arachidonic acid metabolism by phenols: relation to positions of hydroxyl groups and peroxyl radical scavenging properties. Free Radical Biol. Med. 1993, 14, 19-25.

(14) Prior, R. L.; Hoang, H.; Gu, L.; Wu, X.; Bacchiocca, M.; Howard, L.; Hampsch-Woodill, M.; Huang, D.; Ou, B.; Jacob, R. Assays for hydrophilic and lipophilic antioxidant capacity (oxygen radical absorbance capacity $\left(\mathrm{ORAC}_{\mathrm{FL}}\right)$ ) of plasma and other biological and food samples. J. Agric. Food Chem. 2003, 51, 3273-3279.

(15) Xie, J.; Schaich, K. M. Re-evaluation of the 2,2-diphenyl-1picrylhydrazyl free radical (DPPH) assay for antioxidant activity. $J$. Agric. Food Chem. 2014, 62, 4251-4260.

(16) Laaksonen, O.; Mäkilä, L.; Tahvonen, R.; Kallio, H.; Yang, B. Sensory quality and compositional characteristics of blackcurrant juices produced by different processes. Food Chem. 2013, 138, 2421-2429.

(17) Vinson, J. A.; Proch, J.; Bose, P. Determination of quantity and quality of polyphenol antioxidants in foods and beverages. Methods Enzymol. 2001, 335, 103-114.

(18) Fu, L.; Xu, B.-T.; Xu, X.-R.; Gan, R.-Y.; Zhang, Y.; Xia, E.-Q.; Li, H.-B. Antioxidant capacities and total phenolic contents of 62 fruits. Food Chem. 2011, 129, 345-350.

(19) Brand-Williams, W.; Cuvelier, M. E.; Berset, C. Use of a free radical method to evaluate antioxidant activity. LWT Food Sci. Technol. 1995, 28, 25-30.

(20) Blois, M. S. Antioxidant determinations by the use of a stable free radical. Nature 1958, 181, 1199-1200.

(21) Tian, Y.; Liimatainen, J.; Alanne, A.-L.; Lindstedt, A.; Liu, P.; Sinkkonen, J.; Kallio, H.; Yang, B. Phenolic compounds extracted by acidic aqueous ethanol from berries and leaves of different berry plants. Food Chem. 2017, 220, 266-28.

(22) Yang, W.; Laaksonen, O.; Kallio, H.; Yang, B. Effects of latitude and weather conditions on proanthocyanidins in berries of Finnish wild and cultivated sea buckthorn (Hippophä̈ rhamnoides L. ssp. rhamnoides). Food Chem. 2017, 216, 87-96.

(23) Zheng, J.; Kallio, H.; Yang, B. Sea buckthorn (Hippophä̈ rhamnoides ssp. rhamnoides) berries in Nordic environment: compositional response to latitude and weather conditions. J. Agric. Food Chem. 2016, 64, 5031-5044.

(24) Yang, W.; Laaksonen, O.; Kallio, H.; Yang, B. Proanthocyanidins in sea buckthorn (Hippophä rhamnoides L.) berries of different origins with special reference to the influence of genetic background and growth location. J. Agric. Food Chem. 2016, 64, 1274-1282.

(25) Laaksonen, O. A.; Salminen, J.-P.; Mäkilä, L.; Kallio, H. P.; Yang, B. Proanthocyanidins and their contribution to sensory attributes of black currant juices. J. Agric. Food Chem. 2015, 63, 5373-5380. 
(26) Kallio, H.; Yang, W.; Liu, P.; Yang, B. Proanthocyanins in wild sea buckthorn (Hippophä̈ rhamnoides) berries analyzed by reversedphase, normal-phase and hydrophilic interaction liquid chromatography with UV and MS detection. J. Agric. Food Chem. 2014, 62 (31), $7721-7729$.

(27) Kortesniemi, M.; Sinkkonen, J.; Yang, B.; Kallio, H. ${ }^{1} \mathrm{H}$ NMR spectroscopy reveals the effect of genotype and growth conditions on composition of sea buckthorn (Hippophaë rhamnoides L.) berries. Food Chem. 2014, 147, 138-146.

(28) Yang, B.; Zheng, J.; Laaksonen, O.; Tahvonen, R.; Kallio, H. Effects of latitude and weather conditions on phenolic compounds in currant (Ribes spp.) cultivars. J. Agric. Food Chem. 2013, 61, 35173532.

(29) Zheng, J.; Yang, B.; Ruusunen, V.; Laaksonen, O.; Tahvonen, R.; Hellsten, J.; Kallio, H. Compositional differences of phenolic compounds between black currant (Ribes nigrum L.) cultivars and their response to latitude and weather conditions. J. Agric. Food Chem. 2012, 60 (26), 6581-6593.

(30) Zheng, J.; Yang, B.; Trépanier, M.; Kallio, H. Effects of genotype, weather and latitude conditions on the composition of sugars, sugar alcohols, fruit acids and ascorbic acid in sea buckthorn (Hippophaë rhamnoides ssp. mongolica) berry juice. J. Agric. Food Chem. 2012, 60 (12), 3180-3189.

(31) Mäkilä, L.; Laaksonen, O.; Diaz, J. M. R.; Vahvaselkä, M.; Myllymäki, O.; Lehtomäki, I.; Laakso, S.; Jahreis, G.; Jouppila, K.; Larmo, P.; Yang, B.; Kallio, H. Exploiting blackcurrant juice press residue in extruded snacks. LWT -Food Sci. Technol. 2014, 57, 618627.

(32) Rodríguez, J. C.; Gómez, D.; Pacetti, D.; Núñez, O.; Gagliardi, R.; Frega, N. G.; Ojeda, M. L.; Loizzo, M. R.; Tundis, R.; Lucci, P. Effects of the fruit ripening stage on antioxidant capacity, total phenolics, and polyphenolic composition of crude palm oil from interspecific hybrid. J. Agric. Food Chem. 2016, 64, 852-859.

(33) Oh, W. Y.; Shahidi, F. Lipophilization of resveratrol and effects on antioxidant activities. J. Agric. Food Chem. 2017, 65, 8617-8625. 